\title{
Characterization of Asphalt Mixtures in Qatar
}

\author{
Osman El Hussien \\ osmane@ashghal.gov.qa \\ Quality and Safety Department, Public Works Authority (Ashghal), Doha, Qatar
}

\author{
Khaled E. Hassan \\ khassan@irdme.net \\ Infrastructure Research \& Development (IRD QSTP-LLC), Doha, Qatar \\ Khalid Al-Emadi \\ kemadi@ashghal.gov.qa \\ Quality and Safety Department, Public Works Authority (Ashghal), Doha, Qatar
}

\begin{abstract}
The State of Qatar went through a massive road construction program in the last decade as part of the ongoing development of its infrastructure and road transport network. Construction of roads in Qatar generally utilizes imported materials such as aggregate and binders as a result of the scarcity of local construction materials. Characteristics of asphalt mixtures are studied in this research program in order to evaluate mixtures properties in terms of aggregate packing, binder content, voids, mixture density, maximum density and Marshall Stability. Actual mixtures used in the Public Works Authority road projects were analyzed in the research program. Mixtures were prepared following the Qatar Construction Specifications (QCS, 2014). Combined aggregate gradations for different asphalt mixtures were compared with maximum density envelopes for different maximum aggregate sizes. Moreover, regression analysis was used to evaluate the strength of correlations established between different asphalt mixtures properties. The analysis of these mixtures is outlined in terms of general characteristics and consequently, recommendations are given to improve asphalt mixtures performance.
\end{abstract}

Keywords: Asphalt mixtures; Characterization; Qatar construction specifications

\section{INTRODUCTION}

The economic and social development witnessed in Qatar over the past two decades is associated with improved connectivity through a world-class transport road network for the transportation of people and goods. Traffic volumes and loads continue to increase with high demand for improved quality of roads. Asphalt pavement is widely used for road construction in Qatar, and the country relies mainly on imported aggregate and bitumen binder for its infrastructure development. The properties of asphalt materials could vary widely from different sources and during transportation to Qatar, and hence more emphasis is made on the quality of asphalt mixtures and performance criteria.

Asphalt mix design has changed immensely in recent years with more emphasis on end performance testing. The basics of mix design is primarily focused on the Marshall design methods (Asphalt Institute, 2014) of achieving the optimum binder content for a specific grading curve of the aggregate and ensuring a minimum air voids content. The Qatar Construction Specifications (QCS, 2014) adopted the Marshall Mix design and 
provides additional performance criteria based on the Superpave mix design of rutting, fatigue and aging. The Qatar General Organization for Standardization and Metrology (Qatar Standards) issues confirmation certificates of the asphalt mix design for use in pavement projects in Qatar.

The paper reviews the conformity certificates, issued by Qatar Standards for various asphalt mixtures with analyses of the different properties, with the aim of improving the effectiveness of the current specification of asphalt mix design. Recommendations are made to improve the production and construction practice of asphalt mixtures in Qatar to ensure improved long-term performance and sustainability of the road infrastructure in Qatar.

\section{DATA COLLECTION}

The Qatar General Organization for Standardization and Metrology issued conformity certificates for 191 mixtures. The breakdown of the conformity certificates are as follows:

a. 80 wearing course mixtures.

b. 58 base course class B mixtures.

c. 53 base course class A mixtures.

Wearing course has Nominal Maximum Aggregate Size (NMAS) of $25.0 \mathrm{~mm}$, while base course class A has NMAS of $37.5 \mathrm{~mm}$ and base course class B has NMAS of $25.0 \mathrm{~mm}$. Generally, the conformity certificates include combined mixture gradations and Marshall properties such as stability, flow, Marshall quotient, binder content, voids in mix, voids in mineral aggregate, voids filled with asphalt, voids at 400 blows, retained stability and filler to binder ratio. The data were manually transcribed from scans of conformity certificates and supplied in a spreadsheet for analysis.

\section{DATA ANALYSIS}

The data provided was analyzed with the IBM SPSS statistics computer program. Regression analysis was carried out using a single independent variable and multiple independent variables. The Marshall data from the conformity certificates was analyzed for all layers combined and for each layer separately:

a. Using regression analysis to develop a linear model of each dependent variable in terms of all the other independent variables.

b. Using regression analysis to model the relationship between each dependent variable with all the independent variables other than the verification values.

\subsection{Aggregate gradation}

Combined gradations of mixtures are plotted out together with the QCS 2014 specification limits and the 0.45 Fuller curve (Fuller \& Thompson, 1907), in Figure 1 for the wearing course mixtures, in Figure 2 for base class B mixtures and Figure 3 for the base class A mixtures. It can be seen that all the data fall within the relevant permitted envelope, as would be expected given that the data came from conformity certificates. However, the proportions tend to be nearer the upper limit for the coarser sieve sizes and nearer the lower limit for the finer sieve sizes, which is not unusual elsewhere in the world. Figure 3 shows that one gradation of base course class A was out of QCS 2014 limits. Generally, combined gradations for base course Class A showed more diversity compared to other courses, which were following same trends. 


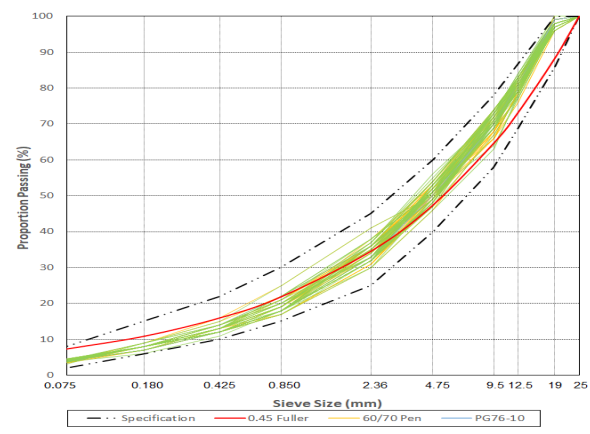

Figure 1: Gradations of asphalt concrete mixtures for surface course

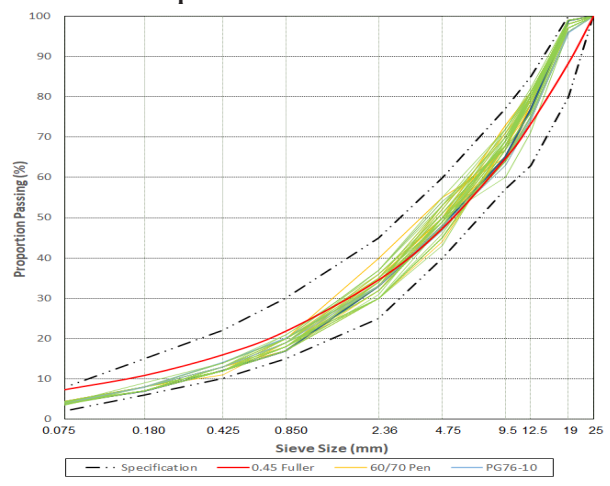

Figure 2: Gradations of asphalt concrete mixtures for base class B
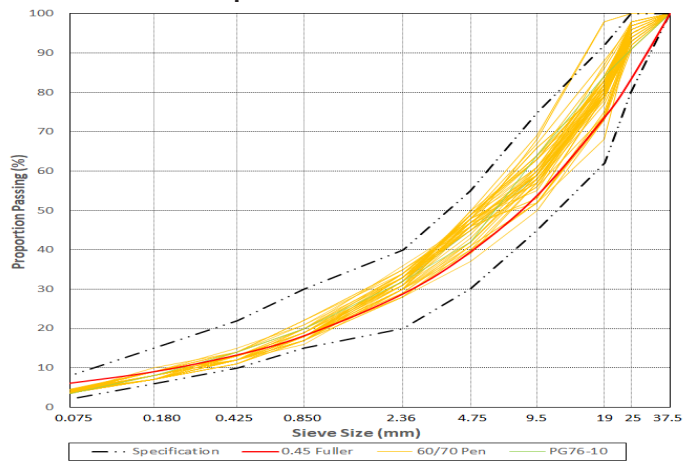

Figure 3: Gradations of asphalt concrete mixtures for base class A

The extent to which the curves cross the sieve sizes relative to the specification range was assessed by the ratio of the value less the lower specification limit and the difference between the two specification limits. The statistics show that the values are all between 0.0 (i.e. on the lower limit) and 1.0 (i.e. on the upper limit). These statistics confirm the visual observation from Figure 1 to Figure 3 that the proportions tend to be near unity for the coarser sieve sizes and smaller for the finer sieve sizes.

\subsection{Binder content}

It is assumed that the target binder content on site is the Optimum Binder Content (OBC) calculated in the Marshall Mixture design process. Based on that assumption, the 
statistics of the binder content found on the conformity certificates are given in Table 1 .

Table 1: Statistics of optimum binder content (\%) from conformity certificates

\begin{tabular}{|c|c|c|c|c|}
\hline Statistic & All layers & Wearing course & Base Class B & Base Class A \\
\hline Limits & - & $3.5-4.0$ & $3.7-4.1$ & $3.3-3.7$ \\
\hline Mean & 3.77 & 3.89 & 3.79 & 3.58 \\
\hline Standard deviation & 0.162 & 0.130 & 0.074 & 0.072 \\
\hline Coefficient of Variation & $4.29 \%$ & $3.36 \%$ & $1.95 \%$ & $2.03 \%$ \\
\hline Range & $3.1-4.0$ & $3.1-4.0$ & $3.7-4.0$ & $3.5-3.9$ \\
\hline
\end{tabular}

The mean values of $\mathrm{OBC}$ for the wearing course and base class A layers are nearer to the specification upper limit than the lower limit, whereas the mean value for the base class B layer, with the highest limits, is nearer to the specification lower limit than the upper limit. When those higher limits are applied to the wearing course results, only one addition case fails. Given that, the gradations are also nearly identical for the wearing course and base class B, with most of the certificates for one layer being capable of being applicable for the other. However, the use for different nominal mix designation is attributed to the fact that base course class B is routinely used as a single layer asphalt course for temporary roads, which are constructed under Road Improvement Works (RIW) program by Public Works Authority (Ashghal).

\subsection{Air voids content}

The statistics of the air voids content of the mixtures (voids) found on the conformity certificates are given in Table 2.

Table 2: Statistics of air voids content (\%) from conformity certificates

\begin{tabular}{|c|c|c|c|c|}
\hline Statistic & All layers & Wearing course & Base Class B & Base Class A \\
\hline Specification limits & - & $5.0-8.0$ & $4.5-8.0$ & $4.0-8.0$ \\
\hline Mean & 6.39 & 6.53 & 6.40 & 6.16 \\
\hline Standard deviation & 0.421 & 0.397 & 0.375 & 0.412 \\
\hline Coefficient of variation & $6.59 \%$ & $6.09 \%$ & $5.87 \%$ & $6.69 \%$ \\
\hline Range & $5.0-7.8$ & $5.5-7.8$ & $5.3-7.3$ & $5.0-7.0$ \\
\hline
\end{tabular}

The variation is quite extensive, with a coefficient of variation around $6 \%$ or more. Despite the variability, all the results comply with the QCS 2014 requirements for the tightest limits imposed on wearing course mixtures. The implication of high air voids contents on the durability of mixtures is considered detrimental even at $8 \%$ (Nicholls, 2017).

\subsection{Mix density}

The statistics of the mix density found on the conformity certificates are given in Table 3. The mix densities have a limited range with coefficients of variation at around $1 \%$. This lack of variation is, presumably, the result of the limited sources of aggregate or at least the similarity in the density between different sources. Nevertheless, the variability that is present can still have an influence on some of the properties of the mixture. 
Table 3: Statistics of mix density $\left(\mathrm{Mg} / \mathrm{m}^{3}\right)$ from conformity certificates

\begin{tabular}{|c|c|c|c|c|}
\hline Statistic & All layers & Wearing course & Base Class B & Base Class A \\
\hline Mean & 2.557 & 2.545 & 2.559 & 2.570 \\
\hline Standard deviation & 0.0340 & 0.0426 & 0.0276 & 0.0147 \\
\hline Coefficient of variation & $1.33 \%$ & $1.68 \%$ & $1.08 \%$ & $0.57 \%$ \\
\hline Range & $2.241-2.736$ & $2.241-2.726$ & $2.518-2.736$ & $2.546-2.614$ \\
\hline
\end{tabular}

\subsection{Maximum density}

The statistics of the maximum density $(\mathrm{Gmm})$ found on the conformity certificates are given in Table 4 . The variability and range are similar to that of the mix density (subsection 3.4), which would normally be expected.

Table 4: Statistics of maximum density $\left(\mathrm{Mg} / \mathrm{m}^{3}\right)$ from conformity certificates

\begin{tabular}{|c|c|c|c|c|}
\hline Statistic & All layers & Wearing course & Base Class B & Base Class A \\
\hline Mean & 2.726 & 2.717 & 2.723 & 2.744 \\
\hline Standard deviation & 0.04308 & 0.05366 & 0.01636 & 0.04086 \\
\hline Coefficient of variation & $1.58 \%$ & $1.97 \%$ & $0.601 \%$ & $1.49 \%$ \\
\hline Range & $2.330-2.908$ & $2.330-2.904$ & $2.678-2.777$ & $2.688-2.908$ \\
\hline
\end{tabular}

\subsection{Marshall stability}

The statistics of the Marshall stability (Stability) found on the conformity certificates are given in Table 5. The range is fairly wide, with coefficients of variation of about 10\%. However, all the results comply with the QCS 2014 requirements.

Table 5: Statistics of Marshall stability $(\mathrm{kN})$ from conformity certificates

\begin{tabular}{|c|c|c|c|c|}
\hline Statistic & All layers & Wearing course & Base Class B & Base Class A \\
\hline Specification limits & - & $\geq 11.5$ & $\geq 9.5$ & $\geq 9.5$ \\
\hline \multicolumn{5}{|c|}{ All binders } \\
\hline Mean & 16.06 & 16.46 & 16.13 & 15.38 \\
\hline Standard deviation & 1.813 & 1.9099 & 1.8163 & 1.4641 \\
\hline Coefficient of variation & $11.29 \%$ & $11.61 \%$ & $11.26 \%$ & $9.52 \%$ \\
\hline Range & $11.2-20.0$ & $12.3-20.0$ & $11.2-19.4$ & $12.1-19.0$ \\
\hline \multicolumn{5}{|c|}{ Penetration grade bitumen } \\
\hline Mean & 15.12 & 15.11 & 14.55 & 15.37 \\
\hline Standard deviation & 1.518 & 1.583 & 1.416 & 1.477 \\
\hline Coefficient of variation & $10.04 \%$ & $10.47 \%$ & $9.73 \%$ & $12.1-19.0$ \\
\hline Range & $11.2-19.1$ & $12.3-19.1$ & $11.2-17.1$ & 15.8 \\
\hline \multicolumn{5}{|c|}{ Performance grade binders } \\
\hline Mean & 17.30 & 17.50 & 17.09 & Single value \\
\hline Standard deviation & 1.380 & 1.435 & 1.287 & Single value \\
\hline Coefficient of variation & $7.98 \%$ & $8.20 \%$ & $7.53 \%$ & 15.8 \\
\hline Range & $13.5-20.0$ & $13.5-20.0$ & $13.5-19.4$ & \\
\hline
\end{tabular}


When comparing the statistics for the mixtures with performance graded binders against the conventional penetration grade bitumen, there is an average increase of about $2 \mathrm{kN}$ but the minimum value is from a performance grade binder. Therefore, it would appear that an enhancement of the Marshall stability generally results from the use of performance grade bitumen, but not always.

\section{CONCLUSION AND RECOMMENDATIONS}

Combined gradations tend to be near the upper specification limit for the coarser sieve sizes and nearer the lower specification limit for the finer sieve sizes.

The 0.45 Fuller curve is contained within the specification envelope but lies close to the lower limit for the coarser sieve sizes and close to the upper limit for the finer sieve sizes with the mixture gradations being noticeably above it at the coarse end and below it at the fine end.

The mixture density and maximum density values have limited ranges with coefficients of variation at around $1 \%$.

The range of air voids content of the mixture values is wide, producing coefficients of variation of around 6\% whilst they are in full compliance with QCS 2014 requirements.

The Marshall stability values have wide range, producing coefficients of variation of about 10\%, but all the values comply with QCS 2014 specifications.

The current gradations of asphalt supplied in Qatar, as represented by the conformity Certificate data, do not respect the restricted zone concept. It is recommended to study the effect of this zone on asphalt laying and performance.

Ideally, it would be better to move towards performance evaluation of Marshall Mixtures for mix design purposes and include tests such as wheel tracking and indirect tensile strength to evaluate mixtures' performance.

\section{REFERENCES}

Asphalt Institute (2014). Mix design methods for asphalt concrete and other hot-mix types. MS-2, 7th Edition, Asphalt Institute, Lexington, the USA.

Fuller, W. B. \& Thompson, S. E. (1907). The laws of proportioning concrete. Transactions of the American Society of Civil Engineers, 59, pp. 67 172, Reston, Virginia: American Society of Civil Engineers.

Nicholls, J. C. (2017). Asphalt mixture specification and testing. CRC Press, London.

QCS (2014). Qatar Construction Specifications. Qatar General Organization for Standardization and Metrology (Qatar Standards), Doha, Qatar. 